\title{
AVALIAÇÃO ERGONÔMICA DE BLOCO ADMINISTRATIVO MILITAR
}

\author{
OLIVEIRA, Valéria Costa de (1); \\ Carvalho, Leandro de Souza (2) \\ (1) Instituto Federal de Rondônia, Mestre \\ e-mail:valeria.oliveira@ifro.edu.br \\ (2) Instituto Federal de Rondônia, Discente do curso técnico em edificações \\ e-mail:leandroejm@gmail.com
}

\begin{abstract}
RESUMO
A ergonomia visa estabelecer parâmetros que permitam a adaptação das condições de trabalho às características psicofisiológicas dos trabalhadores, de modo a proporcionar um máximo de conforto, segurança e desempenho eficiente. $O$ objetivo deste trabalho foi a avaliação da NR $17 \mathrm{em}$ um Bloco Administrativo da Polícia Militar. A metodologia partiu da aplicação de um check list relacionado a ergonomia conforme a Norma do Ministério do Trabalho. Foi observado que esse ambiente de trabalho possui deficiências a respeito do assunto retratado e assim foi proposto alterações de alguns mobiliários, e no layout das salas, sem alteração na parte estrutural do edifício.
\end{abstract}

Palavras chave: ergonomia; conforto; trabalhadores.

\begin{abstract}
Ergonomics aims to establish parameters that allow the adaptation of working conditions to the psychophysiological characteristics of workers, so as to provide maximum comfort, safety and efficient performance. The objective of this work was the evaluation of NR 17 in an Administrative Block of the Military Police. The methodology was based on the application of a check list related to ergonomics according to the Standard of the Ministry of Labor. It was observed that this work environment has deficiencies regarding the subject portrayed and thus it was proposed changes of some furniture, and in the layout of the rooms, without alteration in the structural part of the building.
\end{abstract}

Keywords: ergonomics; comfort; workers.

\section{INTRODUÇÃO}

Ergonomia objetiva interações das pessoas com a tecnologia, a organização e o ambiente para intervenções e projetos que visam melhorar de forma integrada e não dissociada, a segurança, o conforto, o bem-estar e a eficácia das atividades humanas.

Neste sentido o entendimento da complexidade dos fatores envolvidos nas relações estabelecidas entre o coletivo humano, tarefa, máquina e ambiente construído é fundamental para a concepção de ambientes mais adequados às demandas dos usuários e das atividades desempenhadas por eles (FONSECA e RHEINGANTZ, 2009).

Daí a necessidade de se prestar maior atenção ao que acontece quando as pessoas estão pensando e como o ambiente interfere de maneira positiva ou negativa, especialmente nas 


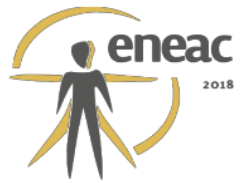

atividades que exigem concentração ou trabalho mental, ou seja, é preciso estudar com mais cuidado como os diferentes tipos de ambientes estimulam o pensamento e sua posterior transformação em ações (SMITH e KEARNY, 1994).

O Ministério do Trabalho tem expedido normas que objetivam resguardar a saúde e segurança do trabalhador. Tais normas receberam a nomenclatura de Normas Regulamentadoras (NR), sendo prevista a obrigatoriedade do seu cumprimento pelos empregadores, na Consolidação das leis do Trabalho(CLT) em seu artigo 155.

Entre as NR's ressalta-se a NR 17 que visa estabelecer parâmetros que permitam a adaptação das condições de trabalho às características psicofisiológicas dos trabalhadores, de modo a proporcionar um máximo de conforto, segurança e desempenho eficiente.

A NR 17 (2007) estabelece as condições de trabalho que incluem aspectos relacionados ao levantamento, transporte e descarga de materiais, ao mobiliário, aos equipamentos e às condições ambientais do posto de trabalho e à própria organização do trabalho. De forma que para avaliar a adaptação das condições de trabalho às características psicofisiológicas dos trabalhadores, cabe ao empregador realizar a análise ergonômica do trabalho, devendo a mesma abordar, no mínimo, as condições de trabalho, conforme estabelecido nesta Norma Regulamentadora.

\section{CONDIÇÕES MÍNIMAS DE TRABALHO CONFORME A NR 17}

As condições mínimas de avaliação da NR 17 para os postos de trabalho são:

- Levantamento, transporte e descarga individual de materiais;

- Mobiliário dos postos de trabalho;

- Equipamentos dos postos de trabalho;

- Condições ambientais de trabalho;

- Organização do trabalho.

Quanto ao levantamento, transporte e descarga individual de materiais são avaliados os pesos das cargas, a idade e sexo dos funcionários, bem como o tipo de fluxo de transporte. A NR 17 releva a posição do funcionário e a caracterização do mobiliário e equipamentos de forma a garantir ao trabalhador condições de boa postura, visualização e operação.

Ainda, a norma regulamentadora NR 17 prevê que locais de trabalho onde são executadas atividades que exijam solicitação intelectual e atenção constantes (salas de controle, laboratórios, escritórios, salas de desenvolvimento ou análise de projetos), são recomendadas as seguintes condições de conforto:

- Nível de ruído aceitável para efeito de conforto será de até $65 \mathrm{~dB}(\mathrm{~A})$ e a curva de avaliação de ruído (NC) de valor não superior a $60 \mathrm{~dB}$, conforme estabelecido na NBR 10152, norma brasileira registrada no INMETRO;

- Índice de temperatura efetiva entre $20^{\circ} \mathrm{C}$ e $23^{\circ} \mathrm{C}$;

- Velocidade do ar não superior a $0,75 \mathrm{~m} / \mathrm{s}$;

- Umidade relativa do ar não inferior a 40 (quarenta) por cento;

- Iluminação adequada, natural ou artificial, geral ou suplementar, apropriada à natureza da atividade. 


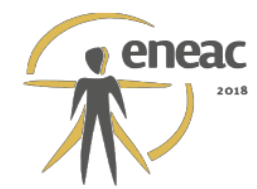

A organização do trabalho, para efeito da NR 17, deve levar em consideração, no mínimo: as normas de produção; o modo operatório; a exigência de tempo; a determinação do conteúdo de tempo; o ritmo de trabalho e o conteúdo das tarefas.

\section{METODOLOGIA}

A pesquisa bibliográfica foi realizada por meio de consulta e aplicação da NR-17 ao posto de trabalho estudado. Os itens avaliados foram quanto ao levantamento, transporte e descarga individual de materiais; mobiliário dos postos de trabalho; equipamentos dos postos de trabalho, condições ambientais de trabalho e organização do trabalho. A partir da análise dos itens estudados foram elaboradas propostas de intervenções para melhoria do ambiente de trabalho.

Desta forma foram elencados os itens da NR 17 que relacionam-se ao ambiente de trabalho analisado na forma de check list (tabela 1), preenchido com as seguintes respostas (C) conforme, (NC) não conforme e (NM) não medido.

Tabela 1-Check list.

\begin{tabular}{|c|c|}
\hline Critério da NR 17 & $\begin{array}{c}\text { (C), (NC) } \\
\text { e (NM) }\end{array}$ \\
\hline $\begin{array}{c}\text { 17.2.2. Não deverá ser exigido nem admitido o transporte manual de cargas, por } \\
\text { um trabalhador cujo peso seja suscetível de comprometer sua saúde ou sua } \\
\text { segurança. }\end{array}$ & \\
\hline $\begin{array}{c}\text { 17.2.3. Todo trabalhador designado para o transporte manual regular de cargas, } \\
\text { que não as leves, deve receber treinamento ou instruções satisfatórias quanto aos } \\
\text { métodos de trabalho que deverá utilizar, com vistas a salvaguardar sua saúde e } \\
\text { prevenir acidentes. }\end{array}$ & \\
\hline $\begin{array}{c}\text { 17.2.4. Com vistas a limitar ou facilitar o transporte manual de cargas deverão ser } \\
\text { usados meios técnicos apropriados. }\end{array}$ & \\
\hline $\begin{array}{c}\text { 17.3.1. Sempre que o trabalho puder ser executado na posição sentada, o posto } \\
\text { de trabalho deve ser planejado ou adaptado para esta posição. }\end{array}$ & \\
\hline $\begin{array}{c}\text { 17.3.3. Os assentos utilizados nos postos de trabalho devem atender aos seguintes } \\
\text { requisitos mínimos de conforto: altura ajustável à estatura do trabalhador e à } \\
\text { natureza da função exercida; características de pouca ou nenhuma conformação na } \\
\text { base do assento; borda frontal arredondada; encosto com forma levemente adaptada } \\
\text { ao corpo para proteção da região lombar. }\end{array}$ & \\
\hline $\begin{array}{c}\text { 17.3.4. Para as atividades em que os trabalhos devam ser realizados sentados, a } \\
\text { partir da análise ergonômica do trabalho, poderá ser exigido suporte para os pés, que } \\
\text { se adapte ao comprimento da perna do trabalhador. }\end{array}$ & \\
\hline $\begin{array}{c}\text { 17.4.1. Todos os equipamentos que compõem um posto de trabalho devem estar } \\
\text { adequados às características psicofisiológicas dos trabalhadores e à natureza do } \\
\text { trabalho a ser executado. }\end{array}$ & \\
\hline
\end{tabular}




\section{CONTINUAÇÃO TABELA 1}

17.4.3. Os equipamentos utilizados no processamento eletrônico de dados com terminais de vídeo devem observar o seguinte: condições de mobilidade suficientes para permitir o ajuste da tela do equipamento à iluminação do ambiente, protegendoa contra reflexos, e proporcionar corretos ângulos de visibilidade ao trabalhador; o teclado deve ser independente e ter mobilidade, permitindo ao trabalhador ajustá-lo de acordo com as tarefas a serem executadas; a tela, o teclado e o suporte para

documentos devem ser colocados de maneira que as distâncias olho-tela, olhoteclado e olho-documento sejam aproximadamente iguais; serem posicionados em superfícies de trabalho com altura ajustável.

17.4.3.1. Quando os equipamentos de processamento eletrônico de dados com terminais de vídeo forem utilizados eventualmente poderão ser dispensadas as exigências previstas no subitem 17.4.3, observada a natureza das tarefas executadas e levando-se em conta a análise ergonômica do trabalho.

17.5.2. Nos locais de trabalho onde são executadas atividades que exijam solicitação intelectual e atenção constantes, tais como: salas de controle, laboratórios, escritórios, salas de desenvolvimento ou análise de projetos, dentre outros, são recomendadas as seguintes condições de conforto: a) níveis de ruído de acordo com o estabelecido na NBR 10152, norma brasileira registrada no INMETRO; b) índice de temperatura efetiva entre $20 \mathrm{oC}$ (vinte) e 23oC (vinte e três graus centígrados);c) velocidade do ar não superior a $0,75 \mathrm{~m} / \mathrm{s}$; d) umidade relativa do ar não inferior a 40 (quarenta) por cento.

17.5.2.1. Para as atividades que possuam as características definidas no subitem 17.5.2, mas não apresentam equivalência ou correlação com aquelas relacionadas na NBR 10152, o nível de ruído aceitável para efeito de conforto será de até $65 \mathrm{~dB}$

(A) e a curva de avaliação de ruído (NC) de valor não superior a $60 \mathrm{~dB}$.

17.5.3. Em todos os locais de trabalho deve haver iluminação adequada, natural ou artificial, geral ou suplementar, apropriada à natureza da atividade.

17.6.4-a) o empregador não deve promover qualquer sistema de avaliação dos trabalhadores envolvidos nas atividades de digitação, baseado no número individual de toques sobre o teclado, inclusive o automatizado, para efeito de remuneração e vantagens de qualquer espécie.

17.6.4-c) o tempo efetivo de trabalho de entrada de dados não deve exceder o limite máximo de 5 (cinco) horas, sendo que, no período de tempo restante da jornada, o trabalhador poderá exercer outras atividades, observado o disposto no art. $468 \mathrm{da}$ Consolidação das Leis do Trabalho, desde que não exijam movimentos repetitivos, nem esforço visual.

17.6.4-d) nas atividades de entrada de dados deve haver, no mínimo, uma pausa de 10 minutos para cada 50 minutos trabalhados, não deduzidos da jornada normal de trabalho.

\section{RESULTADOS E DISCUSSÕES}

O check list foi respondido de forma avaliar os itens da NR17 com a classificação conforme, não conforme e os de não possíveis medição, de acordo com o atendimento desses no bloco Administrativo Militar (tabela 2).

Após o preenchimento do check list para análise de conformidade dos itens da NR 17, foi constatado que, dos 15 (quinze) itens da NR-17, aplicáveis ao bloco da Diretoria Militar, dos 


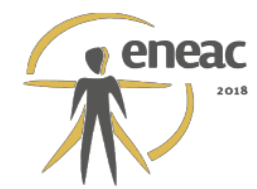

3 (três) itens relacionados a levantamento, transporte e descarga individual de materiais, nenhum está em conformidade com a norma; dos 3 (três) itens relacionados a mobiliário dos postos de trabalho, 1 (um) está em conforme, e 2 (dois) não; dos 3 (três) itens relacionados a equipamentos dos postos de trabalho, todos estão conforme; dos 3 (três) itens relacionados a condições ambientais de trabalho, 1 (um) está conforme e 2 (dois) não puderam ser medidos; e dos 3 (três) que tratam sobre organização do trabalho, todos foram classificados conforme, sendo as justificativas para essa classificação apresentada a seguir.

Tabela 2 - Check list preenchido.

\begin{tabular}{|c|c|}
\hline Critério da NR 17 & $\begin{array}{l}\text { (C), (NC) } \\
\text { e (NM) }\end{array}$ \\
\hline $\begin{array}{l}\text { 17.2.2. Não deverá ser exigido nem admitido o transporte manual de cargas, por } \\
\text { um trabalhador cujo peso seja suscetível de comprometer sua saúde ou sua } \\
\text { segurança. }\end{array}$ & NC \\
\hline $\begin{array}{c}\text { 17.2.3. Todo trabalhador designado para o transporte manual regular de cargas, } \\
\text { que não as leves, deve receber treinamento ou instruções satisfatórias quanto aos } \\
\text { métodos de trabalho que deverá utilizar, com vistas a salvaguardar sua saúde e } \\
\text { prevenir acidentes. }\end{array}$ & NC \\
\hline $\begin{array}{l}\text { 17.2.4. Com vistas a limitar ou facilitar o transporte manual de cargas deverão ser } \\
\text { usados meios técnicos apropriados. }\end{array}$ & $\mathrm{NC}$ \\
\hline $\begin{array}{l}\text { 17.3.1. Sempre que o trabalho puder ser executado na posição sentada, o posto } \\
\text { de trabalho deve ser planejado ou adaptado para esta posição. }\end{array}$ & C \\
\hline $\begin{array}{l}\text { 17.3.3. Os assentos utilizados nos postos de trabalho devem atender aos seguintes } \\
\text { requisitos mínimos de conforto: altura ajustável à estatura do trabalhador e à } \\
\text { natureza da função exercida; características de pouca ou nenhuma conformação na } \\
\text { base do assento; borda frontal arredondada; encosto com forma levemente adaptada } \\
\text { ao corpo para proteção da região lombar. }\end{array}$ & $\mathrm{NC}$ \\
\hline $\begin{array}{l}\text { 17.3.4. Para as atividades em que os trabalhos devam ser realizados sentados, a } \\
\text { partir da análise ergonômica do trabalho, poderá ser exigido suporte para os pés, que } \\
\text { se adapte ao comprimento da perna do trabalhador. }\end{array}$ & NC \\
\hline $\begin{array}{l}\text { 17.4.1. Todos os equipamentos que compõem um posto de trabalho devem estar } \\
\text { adequados às características psicofisiológicas dos trabalhadores e à natureza do } \\
\text { trabalho a ser executado. }\end{array}$ & C \\
\hline $\begin{array}{l}\text { 17.4.3. Os equipamentos utilizados no processamento eletrônico de dados com } \\
\text { terminais de vídeo devem observar o seguinte: condições de mobilidade suficientes } \\
\text { para permitir o ajuste da tela do equipamento à iluminação do ambiente, protegendo- } \\
\text { a contra reflexos, e proporcionar corretos ângulos de visibilidade ao trabalhador; o } \\
\text { teclado deve ser independente e ter mobilidade, permitindo ao trabalhador ajustá-lo } \\
\text { de acordo com as tarefas a serem executadas; a tela, o teclado e o suporte para } \\
\text { documentos devem ser colocados de maneira que as distâncias olho-tela, olho- } \\
\text { teclado e olho-documento sejam aproximadamente iguais; serem posicionados em } \\
\text { superfícies de trabalho com altura ajustável. }\end{array}$ & C \\
\hline $\begin{array}{c}\text { 17.4.3.1. Quando os equipamentos de processamento eletrônico de dados com } \\
\text { terminais de vídeo forem utilizados eventualmente poderão ser dispensadas as } \\
\text { exigências previstas no subitem 17.4.3, observada a natureza das tarefas executadas } \\
\text { e levando-se em conta a análise ergonômica do trabalho. }\end{array}$ & C \\
\hline
\end{tabular}




\section{CONTINUAÇÃO TABELA 2}

17.5.2. Nos locais de trabalho onde são executadas atividades que exijam solicitação intelectual e atenção constantes, tais como: salas de controle, laboratórios, escritórios, salas de desenvolvimento ou análise de projetos, dentre outros, são recomendadas as seguintes condições de conforto: a) níveis de ruído de acordo com o estabelecido na NBR 10152, norma brasileira registrada no INMETRO; b) índice de temperatura efetiva entre $200 \mathrm{C}$ (vinte) e $230 \mathrm{C}$ (vinte e três graus centígrados);c) velocidade do ar não superior a $0,75 \mathrm{~m} / \mathrm{s}$; d) umidade relativa do ar não inferior a 40 (quarenta) por cento.

17.5.2.1. Para as atividades que possuam as características definidas no subitem 17.5.2, mas não apresentam equivalência ou correlação com aquelas relacionadas na NBR 10152, o nível de ruído aceitável para efeito de conforto será de até $65 \mathrm{~dB}$

(A) e a curva de avaliação de ruído (NC) de valor não superior a $60 \mathrm{~dB}$.

17.5.3. Em todos os locais de trabalho deve haver iluminação adequada, natural ou artificial, geral ou suplementar, apropriada à natureza da atividade.

17.6.4-a) o empregador não deve promover qualquer sistema de avaliação dos trabalhadores envolvidos nas atividades de digitação, baseado no número individual de toques sobre o teclado, inclusive o automatizado, para efeito de remuneração e vantagens de qualquer espécie.

17.6.4-c) o tempo efetivo de trabalho de entrada de dados não deve exceder o limite máximo de 5 (cinco) horas, sendo que, no período de tempo restante da jornada, o trabalhador poderá exercer outras atividades, observado o disposto no art. 468 da Consolidação das Leis do Trabalho, desde que não exijam movimentos repetitivos, nem esforço visual.

17.6.4-d) nas atividades de entrada de dados deve haver, no mínimo, uma pausa de 10 minutos para cada 50 minutos trabalhados, não deduzidos da jornada normal de trabalho.

\subsection{Levantamento transporte e descarga individual de materiais}

A atividade exercida pelos funcionários que relaciona-se ao carregamento de materiais de consumo para caminhões que transportam tais insumos às unidades militares, em uma média de duas a três vezes por ano. Cada peso individual carregado varia de $20 \mathrm{~kg} \mathrm{a} 50 \mathrm{~kg}$. Observou-se ainda que não há um treinamento especifico para a realização de tais atividades, sendo que os profissionais mais experientes instruem os mais novos de acordo com suas experiências pessoais.

A figura 1 mostra o documento DMS - Diálogo Mensal de Segurança ao qual os locais de trabalhos que exercem atividades como a Diretoria Militar de Apoio Logístico e Administrativo devem possuir para estarem de acordo com o item 17.2.3 da Norma Regulamentadora 17. 


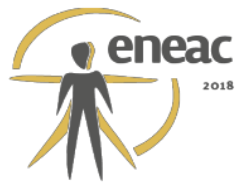

Figura 1 - Diálogo Mensal de Segurança
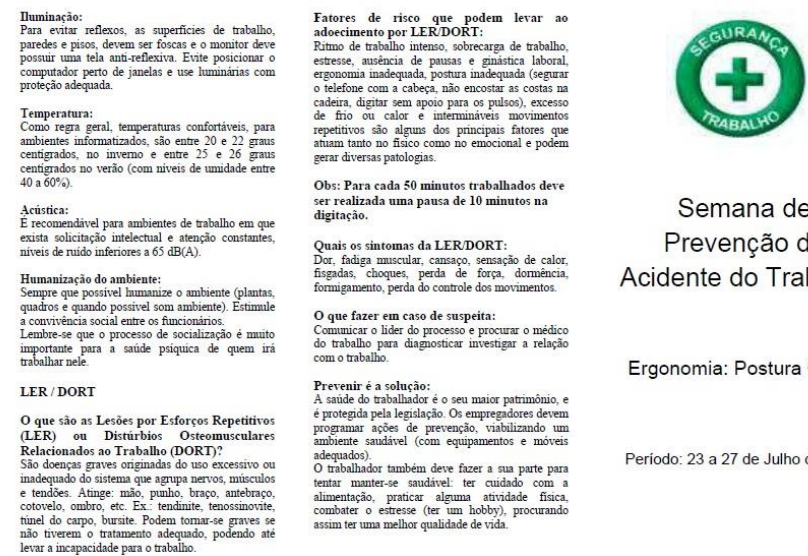

Semana de

Prevenção de

Acidente do Trabalho

Ergonomia: Postura Correta

Periodo: 23 a 27 de Julho de 2012

Dicas gerais de como manter uma boa
postura en um posto de traballo com
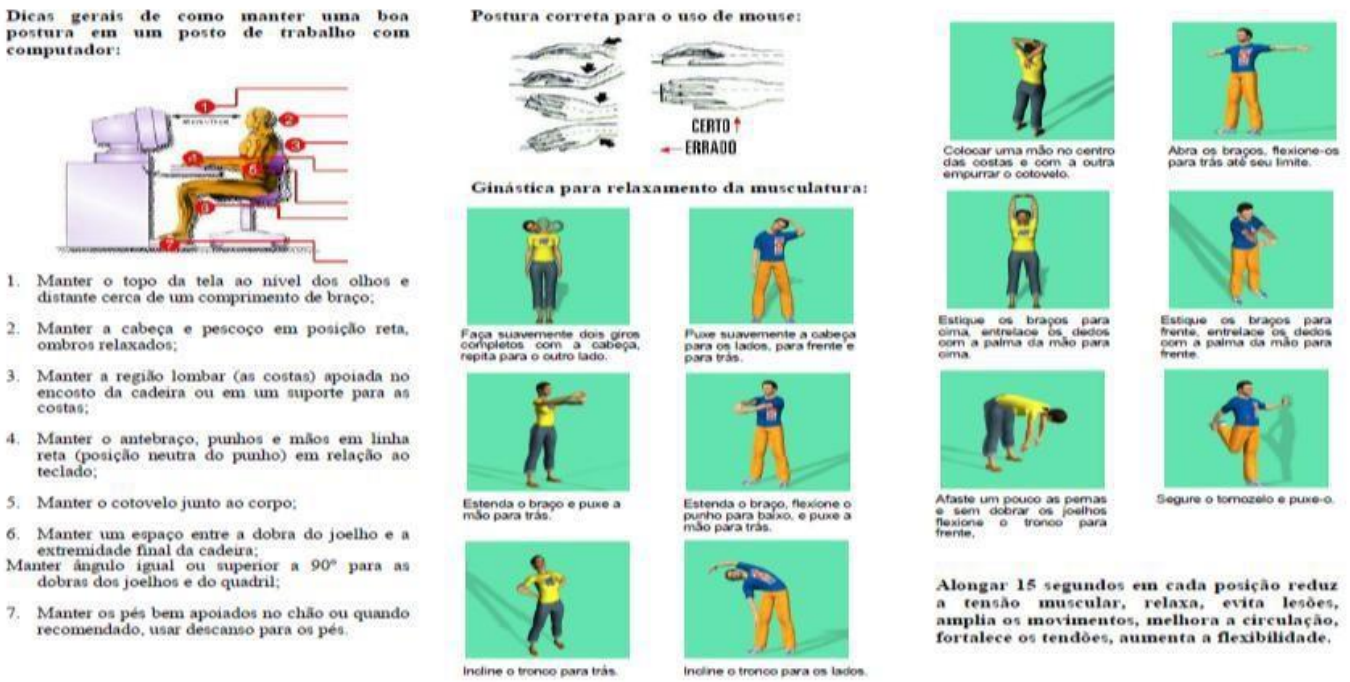

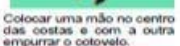

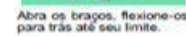
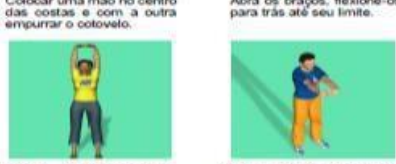

stiave on brages para

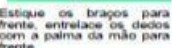

$\infty$
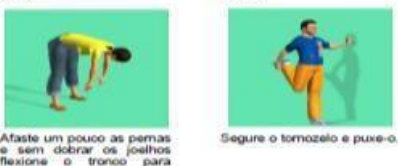

Fonte: Silva, A C (2012)

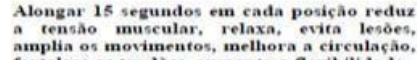
amplia os movimentos, ineliora a circulaçâ.

\subsection{Mobiliário dos postos de trabalho}

É importante salientar que postos de trabalho administrativos da PM devem ser planejados para a garantia de espaços suficientes para mobilidades nas salas, e flexibilidade dos membros superiores e inferiores dos funcionários que exercem suas atividades, a fim de evitar posturas incômodas, levando em consideração pessoas que tenham dificuldade para locomoção.

Foi observado que existem salas em que o espaço para mobilidade é inadequado e incômodo, considerando a atual disposição do mobiliário e a área ocupada pela abertura de portas e gavetas, podendo ser visualizado na figura 2 que mostra $o$ atual layout do bloco Administrativo. 


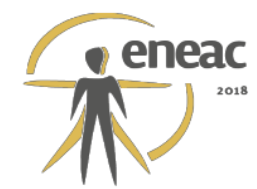

Figura 2 - Layout Bloco Administrativo

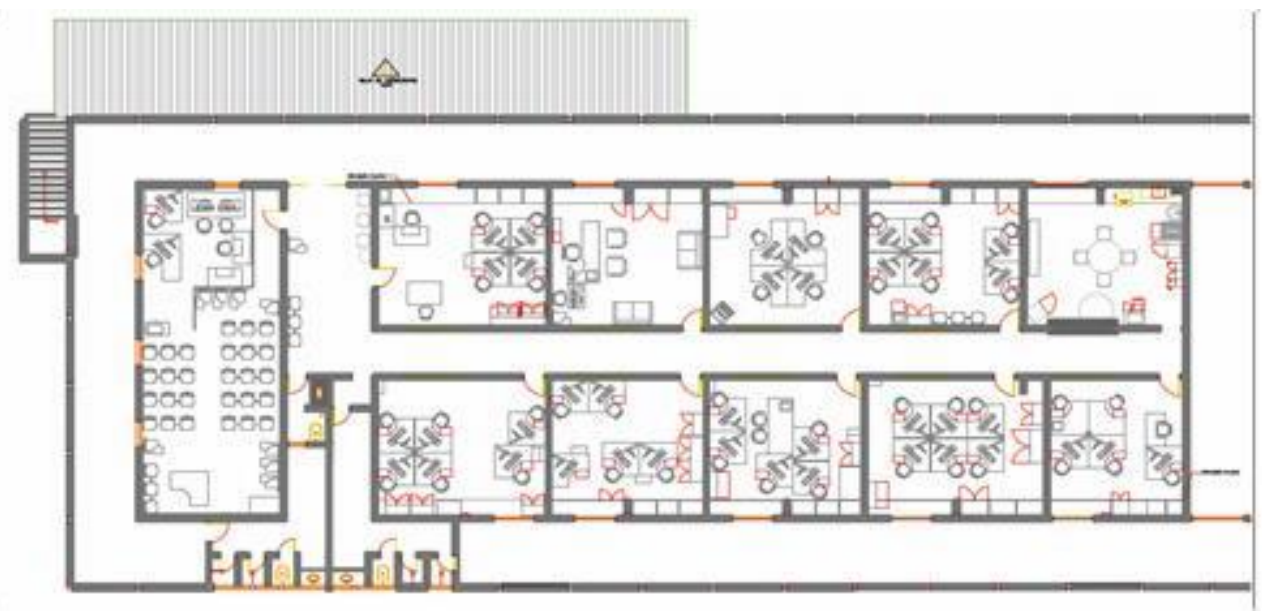

Fonte: Autores

No que diz respeito a adequabilidade dos móveis às exigências da NR17, é dado ênfase nos tipos de cadeiras utilizadas, pois dos três tipos, apenas um atende às especificações previstas em norma (figura 3, a).

Figura 3 - Cadeiras utilizadas.

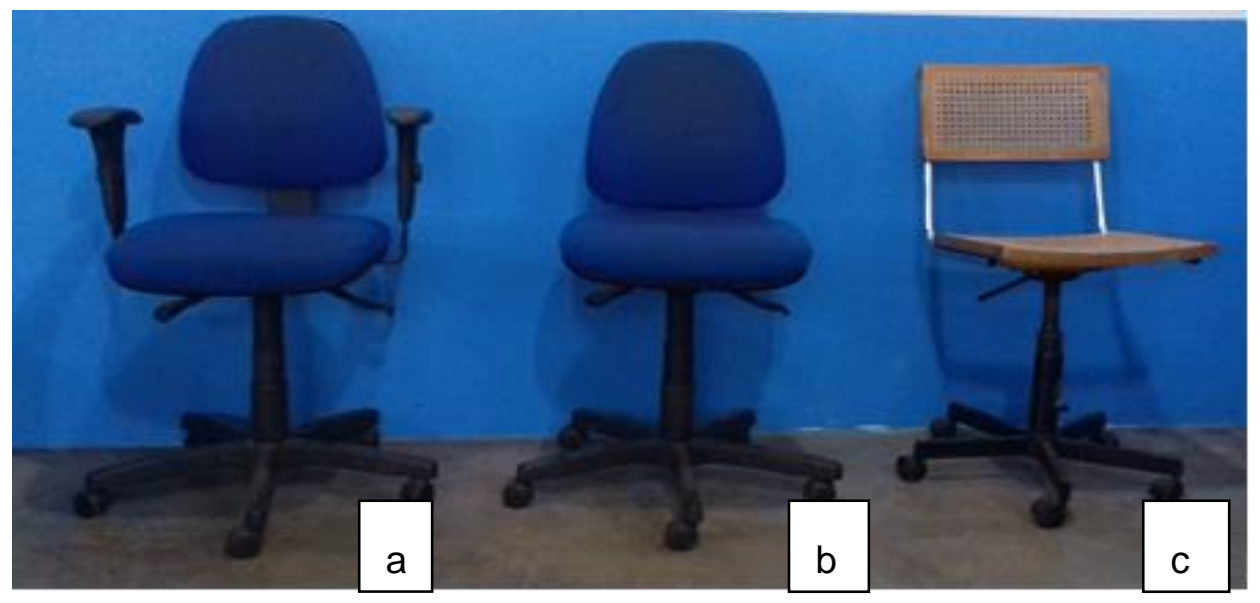

Fonte: Autores

Também, foi proposta uma alteração dos tipos de mesas utilizadas, pois as que se têm atualmente, possuem dimensões superiores às necessárias para as atividades executadas, sendo prevista a utilização de uma mesa com dimensões adequadas para as funções exercidas, altura apropriada, bordas arredondadas e demais exigências da norma.

Quanto aos tipos de armários utilizados (figura 4) para o armazenamento de materiais de expediente, estes poderiam ser adaptados com a instalação de trilhos para substituir as portas com dobradiças e ampliar o espaço para circulação, que antes era ocupado pela abertura das portas. 


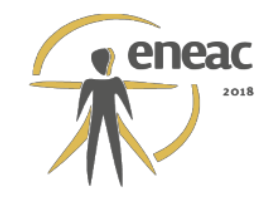

Figura 4 - Armários utilizados.

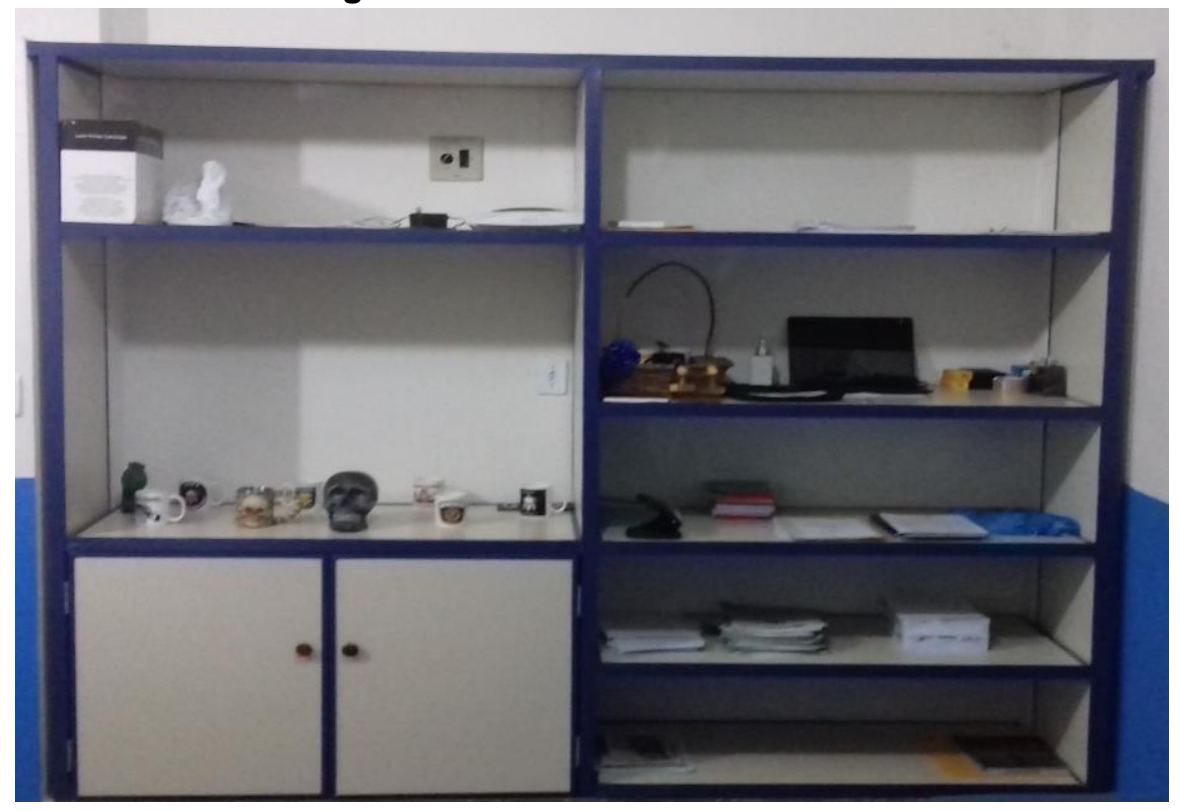

Fonte: Autores

\subsection{Equipamentos dos postos de trabalho}

Os funcionários do local analisado, com exceção de duas funcionárias responsáveis pela limpeza do prédio e atividades da cozinha respectivamente, utilizam sistema eletrônico de informações, estando em conformidade com o item 17.4.3.1; e atendendo às outras especificações do item 14.4 da NR 17.

\subsection{Condições ambientais de trabalho}

Para a análise desse item, não havia disponível equipamentos para a medição de tais características. Porém, foi observado que todas as salas possuem iluminação e ventilação, tanto artificial quanto natural, suficientes para a execução das atividades, e níveis de ruídos adequados, devido ao tipo de atividades exercidas, não havendo quaisquer reclamações por parte dos funcionários relacionadas a esse tópico.

\subsection{Organização do trabalho}

Embora as atividades realizadas ocorram com o auxílio de computadores, não há exigência de tempo para digitação. Com relação ao tempo para pausas, todos os funcionários têm a liberdade para realizar essas, independente do horário de trabalho, não tendo sincronização.

A figura 5 demonstra o layout do bloco administrativo com as alterações descritas. Mostrouse oportuna a proposta de um projeto ergonômico para o bloco Administrativo Militar onde a análise foi realizado, visto que está previsto a realização de reformas no local. Foi observado que esse ambiente de trabalho possui deficiências a respeito do assunto retratado. É destacado que para o desenvolvimento da proposta do projeto, foi levado em consideração modificações que não gerem muitas despesas para a empresa, sendo proposto apenas alterações de alguns mobiliários, e no layout das salas, sem alteração na parte estrutural do edifício, considerando a demanda do local e sua conformidade com a NR 17. 


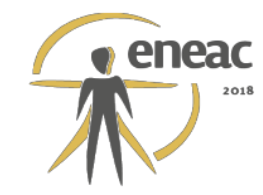

Figura 5 -Proposta de alteração do Layout

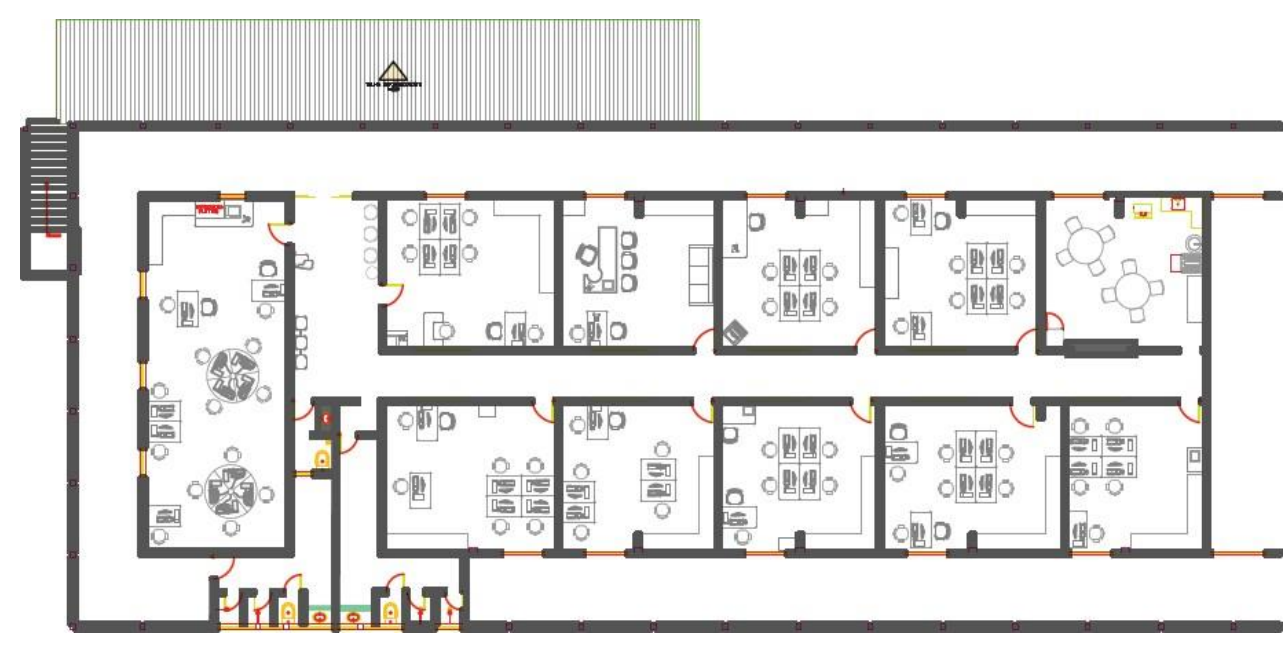

Fonte: Autores

\section{REFERÊNCIAS BIBLIOGRÁFICAS}

FONSECA, J. F. P.; RHEINGANTZ, A. O ambiente está adequado? Prosseguindo com a discussão. Produção, v. 19, n. 3, p. 502-513, 2009.

MINISTÉRIO DO TRABALHO. NR-17: ERGONOMIA., 2007.

SMITH, P.; KEARNY, L. Creating Workplaces Where People Can Think. San Francisco: JosseyBass Publishers, 1994.

SILVA, A. C., Diagnóstico da norma regulamentadora NR-17 em um escritório de uma empresa de distribuição de energia. Pós-graduação em ergonomia e otimização de processo, Faculdade Ávila, Manaus, 2012.

SILVA, C. R., et al. Ergonomia: Um estudo sobre sua influência na produtividade. Revista de Gestão USP, São Paulo, v. 16, n. 4, p. 61-75, 2009. 